\title{
METHODOLOGY OF COMPLEX AND INTERDISCIPLINARY RESEARCHES IN MODERN PSYCHOLOGY
}

\begin{abstract}
The article is devoted to the evaluation of perspectives of interdisciplinary researches using in psychological science in modern conditions. There are formulated approaches that let to improve the efficiency of interdisciplinary researches. Although this issue has received considerable attention of researchers, the problem is not solved at the moment. The theory of complex psychological researches as a scientific concept, reflecting the specificity of psychological research has not been developed yet. The reason for this is that researchers try to develop the principles of organization and procedure of this kind of researches. It is possible to develop the methodology and theory of complex psychological researches, based on the understanding of the subject of psychology. It is alleged that at present time the most adequate understanding of the subject of psychology is his interpretation like the subjective world of human.
\end{abstract}

Keywords: psychology, the efficiency of interdisciplinary researches, the methodology and theory of complex psychological researches.

\section{Introduction}

Nowadays the organization of complex psychological researches is facing significant challenges, so that comprehensive research and development are significantly less effective than it was anticipated. We emphasize the fundamental nature of the problem, because the complex of research effectiveness within psychology (interaction between the branches of psychology) and the organization for interdisciplinary researches (interaction of psychology and other sciences) depends on its solution. Although this issue has received considerable attention of researchers, the problem is not solved at the moment. Theory of complex psychological researches as a scientific concept, reflecting the specificity of psychological research has not yet been developed. The reason for this is that researchers tend to develop procedures and principles of this kind of studies. We 
assume that it is possible to develop a methodology and theory of complex psychological research, based on the understanding of the subject of psychological science. The effectiveness of a comprehensive study in psychology is largely driven by the level of conceptual overlap of understanding and interpreting the subject of psychology in research approaches in those subject areas that will interact in this study, which actually is not included in the currently presented concept of integrated studies in psychology. Consequently, the methodological grounds (and based on the theory of them) should disclose the method of interpretation of the subject matter presented in the scientific approach, realized in a comprehensive study. The novelty of the approach lies in the fact that it is implemented to develop a methodology and theory of complex psychological research, based on psychological science subject understanding.

The development of science, as is well known, as a complex process that includes and differentiation, and integration of knowledge. It is currently a large number of independent scientific disciplines. On the place of psychology in the sciences, to a large extent depends on the solution of two very important issues.

Solving of two very important questions depends on what place role psychology has in the system of sciences: 1) what can psychology give other sciences, 2) to what degree can psychology use the results of research in other sciences. There is no possibility in the present text to follow the evolution of ideas about the classification of sciences and psychology of the place within this classification. We only note that this is a very interesting and promising story.

\section{Methodological problems of interdisciplinary research in psychology}

B.G. Ananyev (1969) in "Human as an object of knowledge" considered the connection between psychology and other disciplines. An analysis of these relationships within Ananyev's concept of integrated human science led to come to the conclusion that psychology synthesizes the achievements of other sciences. Famous domestic psychologist B.F. Lomov in the book "Methodological and theoretical problems of psychology" said: "The most important function of psychology in the general system of scientific knowledge is that it synthesizes the achievement a number of other fields of scientific knowledge, and is an integrator of all (or at least most) of scientific disciplines, which research object is the human being. As Ananyev noted this is its historical mission, connected with it the prospects of its development. Psychology integrates data about a person at the level of specific scientific knowledge. A higher level of integration is the task of philosophy, of course" (Lomov, 1984, p. 19). Lomov (1984) notes that the interaction of 
psychology and other sciences is made through psychological science spheres: in the social sciences through social psychology, in natural - through psychophysics, psychophysiology, comparative psychology, in medical sciences - through medical psychology, abnormal psychology, neuropsychology et al., with educational - in developmental psychology, educational psychology, etc.., with technical - in engineering psychology, etc. An important factor in the differentiation of psychology is precisely relations with other sciences.

Today, at the beginning of the second decade of the XXI century we can we can say that psychology is undoubtedly acquired the status of an independent scientific discipline, although the actual leading central position among other sciences have not received yet. It must be noted in general that the forecasts and expectations were not justified: the status of psychology at all is not so high, and the impact on other disciplines is not as much as it follows from the definition of psychology as a science, which has a special position among others. The publication of A.L. Zhuravlev (2007) "Features of interdisciplinary research in modern psychology" an important event was. The paper is devoted to extremely relevant methodological problems, since in psychology traditionally important place belongs to interdisciplinary research. A.L. Zhuravlev said: "At present, the priority is increasingly becoming a multi-disciplinary research, and this applies not only to the socio-psychology or the humanities, but also to the whole science in general" (Zhuravlev, 2007, p. 15). Interdisciplinary studies have particular importance for psychology, because “... The problem of mental itself is inherently interdisciplinary. There is no monopoly in its study in psychological science: the phenomenon of the mind in its objective nature involves interdisciplinary study" (Zhuravlev, 2007, p. 17).

According to the above-mentioned materials we can make some generalizations that are essential for the theme of our research.

- Future prospects and development of psychology directly depends on its interdisciplinary connections.

- Interaction of psychology and other sciences is made through the branches of psychology.

- Psychology synthesizes the achievements of other sciences.

- Psychology integrates data about a person at the level of specific scientific knowledge.

- It can be identified the most promising areas for the organization of interdisciplinary 
research: in the social sciences through social psychology, with natural - through psychophysics, psychology, comparative psychology, medical sciences - through medical psychology, abnormal psychology, neuropsychology, etc., With teaching - through psychology development, educational psychology, etc., with technical - in engineering psychology, etc.

- The most effective interdisciplinary approaches can be considered those that were made in the late XX - early XXI century and led to the formation of psychology branches. Refersing to the following psychological science branches: engineering psychology (psychology!) as a technical specialty, clinical psychology as medical, social psychology as sociology, psychophysiology as medical and biological specialties.

- Interdisciplinarity in psychology is inevitable, trying to understand the nature of the psychic is fundamentally interdisciplinary, in fact.

- Wrongfully to understand that interdisciplinary research - the only one form of research in psychology.

- The costs are inevitable, that is, negative consequences of interdisciplinary research for the psychology (e.g., reduction of mental to non-mental).

- The idea of levels of interdisciplinary psychology is extremely important is.

- Psychology integrates data about a person at the level of specific scientific knowledge.

- It can be identified long-term prospects for organizing and conducting interdisciplinary research. It is necessary to develop and to take into account the results of the study of a number of other problems, such as psycho-evolutionary, psycho-historical, psycho-genetic, psycho-morphological, etc., the content of which is not only three wellknown problems (psycho-physical, psycho-physiological and psycho-social). We can assume that in the future these and some others (e.g., psychochemical) will be the most relevant areas of research on the nature of the psychic.

- It can be identified the complexity and difficulties of interdisciplinary researches (pluralism of knowledge, which causes difficulties in the integration of the gained knowledge; interdisciplinary studies have low compatibility used languages of different sciences, interdisciplinary research programs include a variety of methods, but often of different levels of their development, etc.).

Methodological problems of interdisciplinary research and the problem 


\section{of the subject of psychology}

Another important area of research on the problems of this article was studies on the development of problems subject which is matter of psychology. The idea of the need to introduce of the context of the development problems of methodology of integrated and interdisciplinary research as a subject matter of psychology is not obvious, therefore there are required additional clarifications. In our opinion, the popularity of reductionism in psychology is directly related to the limited understanding of the subject of psychology. Lets consider this issue in more detailed. Main methodological problem of modern psychology is to develop a new understanding of the subject of psychology. This is necessary to maintain a single subject field of psychology. This idea also needs to be clarified. Try to do it. And researchers in the field of psychophysics, and researchers in the field of transpersonal psychology are researches of one science - psychology. Now it seems that they are representatives of completely different sciences, as all of it is different. Therefore, understanding of the psychology subject must be so that there was a place as for one as for the other both of them. Only such understanding will enable to combine developments of psychologists of different schools and directions. Without such an understanding it is impossible to generalize huge amount of psychology knowledge. This is a very difficult task. It is, incidentally, the total for the domestic and world psychology (no matter how different approaches to the study of the psyche). Correlation and streamlining the existing material on the basis of a new understanding allow psychology to become fundamental science.

The situation with the subject in general is a source of constant misunderstandings. Indeed, in modern psychology, we are dealing with a "multi-step" subject ("declared", "rationalized", "real"). It is important to emphasize that, "closing" the problem without giving it much importance (as is often the case), we lose hope for the establishment of a common understanding of psychology. To have the latest allegations did not seem excessive dramatization of the situation, try to explain it. To illustrate the use of the classics of the XX century psychology J. Piaget (1966). J. Piaget in the chapter devoted to the problem of explanation in psychology, observes: "In fact, it is wondering how many of the major psychologists use negligent physical concepts when they speak about consciousness. Janet uses the expression "the power of synthesis" and "psychological strength". The term "psychic energy" has become widespread, and the expression "work" even beaten. So, one of two things: either at the same time in a latent form they imply physiology and it is remains only to specify, or rather, to measure, or talk about consciousness and resort to 
metaphor because of the absence of any definition of these concepts, comparable with the concepts that are in physical laws and physical causality. In fact, all these concepts are directly or indirectly involving the concept of mass or substance, which makes no sense in the field of consciousness" (Piaget, 1966, p. 190). J. Piaget continues: “... the concept of causality does not apply to consciousness. This concept is applicable, of course, to the behavior of activity and even; hence the different types of causal explanation, which we differ. But it is not "under the jurisdiction" of consciousness sphere, because one state of consciousness is not the "cause" of another state of consciousness, but it is under other categories. From the seven forms of explanation we have listed before only abstract models [...] are applicable to the structure of consciousness, precisely because they can ignore the fact that we call the real "substrate. The reason involves the use of the deduction for such a substrate, and the difference of the substrate from most of deduction is that it is described in terms of material (even when it comes to behavior and activities). Moreover (and this is a test of our hypotheses), the theory of interaction difficulties arises precisely from the fact that it is trying to extend the scope of reason on consciousness itself" (Piaget, 1966, p. 190). This means that real subject is divided between two spheres, that's why it is not surprising that the "animating communication" (Goethe) is also broken and it is not possible to "eavesdrop life" (as always happens in such cases). It remains to take care of that psychic didn't not become an epiphenomenon once again: "All of this raises, therefore, a serious problem, and to the solution, which consists in recognizing of the existence of two "parallel" or isomorphic series could really satisfying create our need for explanation, we would like to see no one of these series are lost of its functional significance, but rather to make it clear, at least, than these disparate ranks that do not have each other causal interaction, nevertheless complement each other" (Piaget, 1966, p. 189).

Of course, Descartes did a lot for psychology, he created methodological possibilities for the emergence of modern psychology. But it is probably not right to absolute its contribution (at the beginning of the third millennium): dualism allowed psychology to become a science, but it is currently prevents become true science - not only independent, but original (counting the uniqueness of its subject). Mental and physiological thus appear in modern psychology broken spaced. It's not even the fact that in this case there is a temptation that as history of psychology has shown it was extremely difficult to overcome in the early days of scientific psychology: the temptation to explain the cause each other's expense. In modern science scientists have learned to resist such temptation. J. Piaget that was already cited in our paper notes: "These insurmountable difficulties pushing most 
of the authors to ensure that assume the existence of two different sets of events, one of which is formed by states of consciousness, and the other accompanying nervous processes (and every state of consciousness corresponds to such a process, and the reverse would be true). Communication between members of one of the series and the other members of the other series is never a causal relationship, and there is a simple correspondence, or as people usually say, "parallelism" (Piaget, 1966, p. 188). There is one step to the recognition of mental epiphenomenon. It is requiring an effort to keep from doing so: "In fact, if consciousness is only the subjective aspect of nervous activity, it is unclear what is its function, since this one is enough nervous activity" (Piaget, 1966, p. 188). The fact that this kind of gap between mental and physiological two "parallel" spheres produced in a way that makes mental lifeless, devoid of self-motion (due to the postulated mental simplicity). Therefore, psychic needs to get the "explanation", through which the mind should get the "movement": it will be made from the outside, due to the fact "what is" the psychic will be explained (it is not important in this case will it be explained "organismically" or "social"). It can be otherwise, in this logic (because it supposed that the subject of "intrinsically simple"!). This seems to be a fatal mistake. Mental exists objectively has a logic of its own motion (as C.G. Jung has shown convincingly). Therefore, the wellknown rule of E. Spranger psychologica - psychological" (to explain psychical through the psychical) is a logicaly justified: if the mental has its own logic of movement, the explanation should occur "within psychology" (in order to save the qualitative features of the psychological explanation). Let us recall that E. Spranger, being a disciple of W. Dilthey, thought that merit of the last one is liberation of psychology from the tyranny of naturally scientific thought. Note that the approach of Jung to the explanation of psychological reality is radically different from the reductionist explanations. It suffices to compare the traditional reductionist approach with Jung amplification method (Jung, 1994). Amplification - is the part of Jung's method of interpretation. "With the help of the association, Jung tried to establish a personal context of the dream; through the amplification, he connected it with universal images. Amplification involves the use of mythic, historical and cultural parallels to clarify and enrich the content of the metaphorical character of the dream ... Speaking about amplification, Jung compares it with weaving of "psychological fabric", which is woven image" (Jung, 1994a, p.19). As William James wisely noted at the time, the psyche is "pre-adapted" to the conditions of life, so perhaps the "logic of explanation" should not be causal, "reducing" but other...

All the difficulties that are fixed in the work of J. Piaget, have a common "origin": modern scientific psychology unsuccessfully defines its own subject. As we think, a new 
understanding of the subject, that is free from the above drawbacks, makes the problem of reductionism in psychology irrelevant. On the other hand, it is clear that the traditional interpretation of the subject closes the way for effective interdisciplinary research, for example, with the physiology. We can say the same about the relationship with other disciplines (e.g. with sociology, cultural studies, etc.).

Not being able to justify implemented approach because of the limited space of paper, briefly discuss only the basic provisions established in previous studies of the author:

1. Insufficient developed communicative methodology and corresponding conceptual apparatus prevents the development of integration processes in psychological science. In the paper the presence of pretheory as preliminary knowledge prior to the conduction of research (often it is not formulated by the researcher, so do not be reflected in the text) (Mazilov, 2003) is shown. Reconstruction of real content of pretheory is a prerequisite for meaningful correlation of psychological concepts.

2. A study on the development of a framework of communicative methodology aimed at establishing a model It was carried out that let to correlate the actual various psychological concepts (Mazilov, 1998, 2006). It was formulated the main directions of communicative methodology use that has created a real basis for the implementation of integrative processes. The most important results of this phase of the study was that it had proposed a particular technology of various psychological concepts correlation, it was described as method of determining the real and imaginary spectrum of values of basic psychological concepts developed in the light of a layered approach.

3. Another important stepping stone was the development of a methodology focused on the integration of psychological knowledge, and supporting the methodological constructions, creating a foundation for building a specific technology of the integration of psychological knowledge implementation (Mazilov, 2001).

4. It has been shown that the level approach to the understanding of the psychology subject is necessary. It was identified the levels of subject (declared, rationalized, real), were define a function that must fulfill by the concept of "subject of psychology" in the structure of psychological knowledge. It has been shown that a limited understanding of the subject of psychology, that is characteristic for modern science in general, leads to difficulties in the organization of interdisciplinary researches and inevitably leads to reductionism in one form or another (Mazilov, 1998, 2007, 2006). 
5. It the cognitive methodology was, is developed which provides the inclusion of private methodological concepts: the subject of psychology, its method, psychological theory, explaining in general methodological space that opens up new prospects, particularly for complex investigations. Important methodological basis in the development of the theory of complex psychological researches is the concept of integrative cognitive methodology, the general methodology of psychology, in which the individual methodological categories are correlated in a single semantic space. Exactly in their conceptual correlation a new provision of methodological research and development is seen.

6. It has been shown that the efficiency of complex psychological research is largely determined by how close is the understanding of the subject in the scientific approaches of different branches of psychology. This makes it necessary to consider the differences in the understanding of the subject in the time-personal areas of psychology within the organization of a comprehensive study.

In the subject matter of psychology, the main findings can be summarized as follows. There are developed the formal requirements for the subject matter of psychology, refined functions that perform the subject of psychology are developed, the basic characteristics of the subject. It is developed the approach that allow specifying the level understanding of the subject matter of psychology is developed carried out. It is developed the broad understanding of the subject matter of psychology, allowing "non-reductionistic" correlateing different subject areas of psychology. It substantive content of the construct "inner human world" with regard to the formal requirements of the subject of psychology is carried out.

In view of the special importance of this research for this project we will focus on this issue in more detail. It is our deep conviction that is necessary to develop the concept of the subject. The problem of the subject of psychology is the most important methodological problem, which is complex and confusioning (in our opinion). The complexity is "objective" because of the complexity of the object of science. Probably the psyche is the most difficult of what people should comprehend (and, we think, in a very great extent will comprehend in the future). Confusion, on the other hand, comes from the "subjective" reasons. There are many contexts in which different actors use the term the subject of psychology. It is used in different cases for different purposes, which generates a set of understandings and interpretations. The reluctance of the psychological community to organize and deal with these issues only exacerbates the severity of the 
problem.

The confusion begins with the fact that the subject of science and its object are "linked" closely: recall that the subject itself is defined through the object (lat. Objectum "in front of me"). However, in some languages (including, for example, Russian or German) the ability to dissolve the object and the subject exists. As far as we can judge, the concept of "subject" (of course, we are interested in the gnoseological sense) was introduced by the Austrian philosopher R. Amezeder in 1904) to designate some integrity, isolated from the world of objects in the process of human activity and knowledge. Amezeder distinguished subject and object: a unified theory of the object can be created by adding the substantive sections (Baronene, 2002).

In domestic science methodology it has developed the distinction of the subject and the object of science: the object of science is part, an objective existing reality fragment, the subject - an object that is interpreted in terms of one or another a science. This distinction (with all its conventions) is useful for psychology: hence, in particular, it follows that the human psyche is (or could be) the object of many sciences (psychology has not a monopoly on the study of the psyche), but each of Sciences highlights in psyche its own subject, correlating with the conceptual framework of this science. For psychology, this turns into a paradox: in fact, to highlight the subject of psychology (and it often anyway interpreted psyche) in the object psyche, it first must be set. We believe, following Jung, that psychology is not yet fully aware of this paradox: "Sometimes I even think that psychology has not yet realized the volume of its tasks, as well as a complex, confusing nature of psyche. We just begin to aware more or less clearly of the fact that something that is understood by us as a mental is an object of scientific research" (Jung, 1994, pp. 12-13). Here we just note that the mind can be studied by various sciences, so within the organization of complex interdisciplinary research, it is important to take into account differences in the interpretation of the subject.

First of all, note that there may be many subjects. Understanding (interpretations) of the subject varies depending on what purpose science stands the subject. Without claiming completeness, let's identify several objectives, according to which can be given the interpretation of the subject of psychology.

1.The subject is given to constitute of psychology as a science. Physiological psychology of Wundt could be the example of science about direct experience. Wundt introduces the concept of direct experience as the subject of psychology in order to proclaim psychology as independent science that is different from philosophy. 
2. The subject is given to determine the area of research. This is the most common case. When as a subject of psychology is believed, for example, consciousness or behavior, the concept of the subject is used in order to specify the scope of the study.

3. Differentiation of the object in order to clarify the research positions (and to achieve the necessary scientific ideals). For example, F. Brentano distinguishes in consciousness as in a research subject acts of consciousness (in opposition to their content, which, in his opinion, is not a subject of psychology), and E. Titchener from consciousness as the subject of psychology leaves only the mental processes, eliminating the subjectivity which he qualifies as a stimulus error.

4. The subject of science is a means of objectifying of the problem. An example is I.P. Pavlov, who saw in the conditioned reflex the richness of psychic life, or $M$. Wertheimer, who in stroboscopic effect ("phi" - phenomenon) saw the reality of the phenomenal field.

Another aspect that complicates the problem of psychology subject discussion is the principle of multiple approaches to the analysis of the subject of psychology. This is worth dwelling in more detail. Do not attempt to provide an exhaustive listing, we point out that there are possible the various approaches to the analysis of psychology subject.

It is possible the theoretical analysis of the subject. In our opinion, this is one of the main objectives of the methodology of psychological science. One of the first in the recent history of Russian psychology the need for such an analysis has noted I.P. Volkov (2003). In our opinion, the theoretical analysis of the psychology subject should answer the question, what are the functions of the psychology subject in modern science, what should be the main features of the subject of psychology. Note that this approach to the analysis of the subject with all its urgency is developed in the least degree. Such an analysis was tried to make earlier in several papers (Mazilov, 1998a, 2006, 2007) and further (in the present text) we will focus on the prospects of this approach in more detail.

It is possible to analyze psychology subject meaningfully. This is the most common and most developed approach. Each original direction in psychology creates its own understanding of the subject (what is included in the subject and how it is treated). In the history of psychology (with a Brentano light hand (Brentano, 1874) it is determined by the expression "from the point of view": "from an empirical point of view", from "the standpoint of a behaviorist", etc. It can be analyzed in terms of the philosophy of science, when psychological issues of subject and object determination is treated on the basis of general scientific approach. An example is the analysis, carried out by well-known methodologist of 
science E.G. Yudin (1978).

It can be realized the comparative-historical approach to the analysis of the subject of psychology. This is a retrospective analysis, which aims to capture the changes in the understanding and treatment of the subject of psychology at different stages of development). This approach is widely represented in the historical-psychological literature (Yaroshevskiy, 1985), and others.

Theoretical analysis of the subject, in our opinion, involves first identifying of the functions that should be undertaken by the subject of psychological science, as well as its main characteristics.

It seems that we can talk about the next functions.

1. The constituting of science. This is the main function of the subject. The understanding of the subject of science makes possible the existence of some field of knowledge as an independent scientific discipline, independent and distinct from other (Mazilov, 1998).

2. Maintenance of work of the "machine of subject". It is understood that the subject must be capable of movement in the subject field of psychological science at the expense of intrasubject correlations and research procedures to produce growth of objective knowledge.

3. Providing the function of subjective "operationally table" (M. Foucault), which would allow to correlate real the results of studies carried out in different approaches and schools.

4. Didactic function associated with the construction of the content of school subjects.

Here are the main characteristics of the subject.

1. The subject should exist really, should not be "artificially" constructed (in order to be the subject of science in the true sense of the word), i.e., it should not be the property of any other items, and should be investigated psychic reality (in other words, the object must have ontological status).

2. The subject should be internally complex enough to contain essential that identify their own laws, existence and development, rather than a simple set of internal mental to something externality, thus providing a reduction of the psychic.

3. Understanding of the subject should allow making the science of psychology to develop its own logic, without reducing deployment psychological content to psychology 
alien logic or hermeneutic of natural knowledge.

Understanding of psychical as a property of matter makes impossible to study the mental as objectively existing reality.

"Closure" of psychical on physiology (meaning attempts committed with persistence worthy of a better cause) deprives the mental of self-propulsion, energy characteristics. Therefore, it is absolutely inevitable to discovery "causes" in biology, in society, in the logic. The result is that the mental is deprived of its own laws: to the mental are transferred or mechanical (chemical, thermodynamic, synergies and so on.) or hermeneutical laws. But the main thing is that in this approach the psychological inevitably boils down to not psychological. Meanwhile, the well-known requirement of Eduard Spranger ("psychologica-psychological") is still relevant for psychology. Needless to say, that while mental understood as a reflection, there is no real possibility of correlation studies that examined, for example, the response to a given signal, and, for example, transpersonal phenomena, although they certainly belong to different one problematic fields of science psychology.

The situation with the subject in general is a source of constant misunderstandings. It is important to emphasize that, "closing" the problem (as is often the case), we lose hope for the establishment of a common understanding of psychology. It seems that the problem is now central to the subject of psychology. And it is necessary not only case studies that discuss a particular interpretation of the subject, but the actual development of the concept of the subject.

Recall that the problem of the subject has another difficulty. We have already touched on this point, try to give further explanation. For many years, our psychology was in a state of ambivalence. Let us explain this. The official subject of psychology has been of psyche. We call this the declared object. The analysis shows that the subject of psychology has a complex structure. Its original foundation is a basic understanding of "Psyche". As it is often with the case of the fundamental assumptions, they may not be aware of the researcher, and their place may take this or that "rationalization". Thus, there is a division on the subject of the declared ("Psyche"), streamlined and real. The declared subject (more precisely, its interpretation) is important for psychology, primarily because implicitly but effectively defines the possible range of spaces of psychic reality. The fact that within the same understanding of course is a mental phenomenon worthy of study, while the other is an artifact, an accident, or absurd, and as a scam would not exist at all. For example, transpersonal phenomena are unquestionable reality for supporters of 
analytical psychology and "absolutely impossible phenomenon" for natural scienceoriented psychologist, is considered a mental phenomenon only "property of the brain". Between declared and rationalized subjects (in the case where it exists) develops such an attitude: he ("rationalized") "draws" captures a particular interpretation of "Psyche". The real subject - is that really should be studied (an infinite number of options in the "consciousness / unconsciousness - activity / behavior" system).

We have already written that the impartial analysis can reveal an amazing picture. For example, a researcher-psychologist believes that studying the psyche (the declared subject). Rationalized subject may be a reflection (our researcher is studying, for example, the perception - "holistic reflection of objects, situations and events that occurs when the direct effects of physical stimuli on the receptor surface ..." (Petrovskiy, Yaroshevskiy, 1990 , p. 66). Note that at the level of rationalized subject the whole multidimensionality of psyche (and spiritual, and emotional) is reduced to reflect. But the most interesting thing is coming. Because it is studying the real subject. And as a real subject or phenomena acts the self-consciousness in one form or another, or, in general, behavioral (in the broad sense). But this is only the subject of science. Psychologist during the research, as we know, is dealing with the subject of the study. The subject of the research must conform to the subject of science ... We can say that it is constructed by the subject of science.

\section{Conclusion}

Currently it is obvious that the interpretation of psychical as just a reflection is not complied with the requirements of psychological knowledge, creates insurmountable difficulties in the development of psychology. It is needed a new understanding of the subject, allows to include in the scope of research psychic reality in all its forms. In our opinion, creation of such an understanding can be based on the concept of the subject of psychology, we believe that it is the most important task of the methodology of psychology at the present stage of its development. And researchers in the field of psychophysics, and researcher in the field of transpersonal psychology presents one science - psychology. Now it seems that they are representatives of completely different sciences, because all is different. Therefore, understanding of the psychology subject should be such that there was a place as for one and for the other. Only such an understanding makes it possible to combine the achievements of psychologists of different schools and directions. Without such an understanding it is impossible to generalize the huge amounts of knowledge of psychology. This is a very difficult task. It is, the common for the domestic and world psychology (no matter how different approaches to the study of the psyche). Correlation 
and streamlining of the existing materials on the basis of a new understanding will allow to psychology to become fundamental science. In solving of this problem, there are two aspects, or rather, two steps to solve it. The first stage - the formal description of the subject (what functions it must perform, what criteria match). The second stage - the substantive content of the concept "subject of psychology". In this direction the work is carried out. How exactly will this new subject have called? It seems that the most successful is the term "human inner world".

It allows, in our opinion, to carry out substantive content, instead of the whole psychic reality in its entirety. Many methodological problems of psychology generated by the unresolved of main problem - to develop a new understanding of the subject. Confronting of paradigms, the differences between the sciences and the humanistic orientations in psychology, etc. - these major problems are consequences of unresolved fundamental question of psychology. The problem of the subject - it is really, basic question of all, especially of modern psychology. Without its solution it is difficult to hope for a qualitative progress of comprehensive research. Note that this content can overcome traditional psychology difficulties.

In recent years, new approaches to the study of the individual appeared. In our opinion, it is an interesting attempt to consider the person's inner world as the basis of personality. The potential of this approach stems from the fact that allows you to "build bridges" between the mental processes, on the one hand, and the individuality and personality of the other. It is no secret that the traditional understanding of the subject of psychology, they largely are "broken", and from the "sentencing" of the word psyche special "convergence" is usually not exist. Moreover, today it is clear that academic psychology, as "the heir to direct" of Cartesian dualism cannot explain the activity of the psyche. If it still manages to make in the field of knowledge somehow, in the field of personality psychology difficulties become almost insurmountable.

Correlation and streamlining of the existing material on the basis of a new understanding will be the important stage in the establishment of psychology as fundamental science and, on the other hand, a prerequisite for making effective integrated studies.

\section{References}

Ananyev B.G. (1969) Chelovek kak predmet poznanya. (Man, as a subject of knowledge). 
Leningrad: LGU.

Baronene S.G. (2002) Osobennosty objekta issledovatelskoy pozicyy $v$ gumanitarnom issledovanyy. Gumanitarnoye issledovanye $v$ obrazovanyy: opyt, razmyshleniya, problemy. (Features of the object of the research position in humanitarian research. Humanitarian research in education: experience, reflection, problems) Tomsk, 232-244.

Volkov I.P. (1996) Perspektivy razvitya teoreticheskoy I prakticheskoy psihologyy $v$ Rossyy: vozrodit nauchnye issledovanya po predmetu psihologyy. Vestnik Baltiyskoy Akademyy. (Prospects for the development of theoretical and practical psychology in Russia: to revive research on the subject of psychology. Bulletin of the Baltic Academy), N. 3. p. 6-13

Juravlev A.L (2007) Osobennosty mejdisciplinarnyh issledovaniy $v$ sovremennoy psihologyy. Teorya i metodologya psihologyy: pod red. A.L. Juravleva, A.V. Yurevicha. (Features of interdisciplinary research in modern psychology. Theory and Methodology of Psychology: Ed. A.L. Zhuravleva, A.V. Yuryevich) M.: IPRAN, p. 15-32.

Lomov B.F. (1984) Metodologicheskiye i teoreticheskiye problemy psihologyy. (Methodological and theoretical problems of psychology) M.: Nauka.

Mazilov V.A. (2007) Metodologiya psihologicheskoy nauky: istoriya i sovremennost. (The methodology of psychological science: history and modernity). Yaroslavl: MAPN.

Mazilov V.A. (2003) Naucnaya psihologiya: ternistiy put $k$ integracyy. Trudy Yaroslavskogo metodologicheskogo seminara: metodologiya psihologyy. (Scientific psychology: the thorny path to integration. Proceedings of the Yaroslavl Methodological Seminar: Psychology Methodology). Yaroslavl MAPN. pp. 205-237.

Mazilov V.A. (2006) O predmete psihologyy. Metodologiya i istoriya psihologyy. (On the subject of Psychology. Methodology and History of Psychology) T. 1, N 1. pp. 55-72.

Mazilov V.A. (2001) Psihologiya na poroge XXI veka. (Psychology on the threshold of the 21 st century). Yaroslavl, MAPN.

Mazilov V.A. (1998) Teoriya i metod v psihologyy. (Theory and Method in Psychology). 
Yaroslavl, MAPN.

Mazilov V.A. (1998) Utraty i obreteniya: estcho raz o predmete nauchnoy psihologyy. Psihologiya I praktika: Ejegodnik Rossiyskogo Psihologicheskogo Obstchestva. (Losses and gains: escho times about the subject of scientific Psychology. Psychology and Practice: Yearbook of the Russian Psychological Society) T. 4, N. 5 / otv. red. A.V. Karpov, V.A. Mazilov. Yaroslavl. pp. 49-54.

Piaget J. (1966) Harakter obyasneniya $v$ psihologyy i psihofiziologicheskiy parallelism. Fraisse P., Piaget J. Experimentalnaya psihologiya. (The nature of the explanation in psychology and the psychophysiological parallelist. Fraisse P., Piaget J. Experimental Psychology), N. 1, 2. M.: Progress. pp. 157-194.

Petrovskiy A.V., Yaroshevskiy M.G. (1990). Psihologiya: slovar. M.: izdatelstvo politicheskoy literatury. (Psychology. Dictionary M.: publishing house of political literature).

Rogovin M.S. (1969) Vvedenie v psihologiyu. (Introduction to Psychology) M.

Semyuelz E. Shorter B., Plot F. (1994) Kriticheskiy slovar analiticheskoy psihologyy. (Critical Dictionary of Analytical Psychology). C. Junga. M.

Yudin E.G. (1978) Sistemny podhod i princip deyatelnosti: Metodologicheskiye problemy sovremennoy nauki. (System approach and principle of activity: Methodological problems of modern science) M.: Nauka

Jung C.G. (1994) Analiticheskaya psihologiya. (Analytical Psychology). SPb.

Jung C. (1994) Vospominaniya, snovideniya, razmyshleniya. (Memories, dreams, thoughts) Kiev.

Yaroshevskiy M.G. (1985) Istoriya Psihologyy: 3-e izd. (History of Psychology.3-rd edition) M.: Mysl.

Brentano F. (1874) Psychologie vom empirische Standpunkte. Bd. 1. Leipzig: Duncker \& Humblot. 